While we need not, in Great Britain, be unduly alarmed by such figures as these, the fact remains that clean milk is a vital concern of the whole community. If the farmer and the veterinary surgeon do their best to give us clean cows and clean milking, we should see to it that the bottling and distributing organizations do not introduce disease. The householder has an important responsibility too-he should see that used bottles are well washed in hot water before they are returned to the roundsman, especially if there is communicable disease in the house. The problem is complex, requiring, like so many features of our modern civilization, the willing co-operation of all who take part in the chain of operations which link the producer with the consumer. The authors of this paper are to be congratulated on the completion of a very complex and difficult piece of public work. Before they could do it they had to work out methods which are valuable contributions to knowledge.

G. LAPAGE.

\section{PALAONTOLOGY WITHOUT FOSSILS IN THE 'BIRD-WING' BUTTERFLIES}

$\mathrm{E}$ VER since the days of the immortal Wallace, biologists have been intrigued with the distributional problems presented by the fauna of the Malay Archipelago. Probably the butterflies have proved more attractive than any other group, not only on account of their æsthetic charm, but also because the pattern and colour of their wings are susceptible to modification by isolation and climate. There is no doubt that Wallace had the butterflies in mind when he wrote in 1869 : "It is certainly a wonderful and unexpected fact, that an accurate knowledge of the distribution of birds and insects should enable us to map out lands and continents which disappeared beneath the ocean long before the earliest traditions of the human race".

The latest contribution to this subject is of considerable interest and is described by the author, Dr. F. E. Zeuner, as "palæontology without fossils".* Essentially, it comprises an attempt to reconstruct phylogenetic trees for the 'bird-wing' butterflies on the basis of the morphology of the species-groups and the present distribution, and the evolutionary patterns thus obtained are compared with the geological history of the Malay Archipelago. The more or less complete agreement found between these two methods of approach is highly satisfactory.

In order to obtain the requisite data for an accurate division of the 'bird-wing' butterflies into speciesgroups, a considerable amplification of previous systematic work on this genus has been necessary, and this has been carried out principally on the basis of the male genitalia. Accordingly, the 'bird-wing' butterflies are divided into two major groups, the Troides Hübner + Trogonoptera Rippon group and the Ornithoptera Boisduval + Schoenbergia Pagenstecher group.

The phylogenetic trees for these two major groups are reconstructed on the reasonable assumption that each of the groups of subspecies existing at the present time has been derived from a common

- Studies in the Systematies of Troides Hübner (Lepidoptera Papilionidae) and its Allies : Distribution and Phylogeny in Relation to the Geological History of the Australasian Archipelago.
F. E. Zeuner. Trans. Zool. Soc. Lond., 25, 107-184 (1943). ancestral form in comparatively recent times and that, at some earlier period, each of the species. groups present to-day was a subspecies-group, and so on until a stage is reached when there was a common ancestor for each of the two major groups. All the known species of the Troides + Trogonoptera group can be obtained from a single parent-form on the assumption that this division into subspecies which eventually became differentiated into species has taken place at least five times. There can be little doubt that the common ancestor of the essentially western Troides complex originated in Sundaland, that is, in the continental land-mass formed by the union of the Malay Peninsula, Sumatra, Java and Borneo in the Tertiary. The Ornithoptera + Schoenbergia group can also be reduced to a single form on the assumption of five successive phylogenetic waves. While it is clear that the Ornithoptera complex of species has developed in the Papuan area, its past history is by no means so manifest as that of the Troides group for, in its earlier stages, the distribution of Ornithoptera proper was discontinuous, representatives being confined to the Moluccas and the Solomon Islands, while there was an interclave of Schoenbergia in New Guinea.

Regarding the geological history of the Malay Archipelago, it is evident that the continual fluctuation in the sea-levels between the Malay Peninsula and the islands of Sumatra, Java and Borneo, which resulted in these lands being united and separated repeatedly during the Pleistocene, was a factor of outstanding importance as regards species formation in the Archipelago, and accounts for the very large number of groups of closely allied species existing in Malaysia to-day. Of less importance were the changes in sea-level between the Aru Islands, New Guinea and Australia on the Sahul Shelf during this period, although the effects were similar. The remaining large island groups were isolated throughout the periods under discussion.

The formation of a large number of the geographical races (subspecies) found in Malaysia and in the region of the Sahul Shelf to-day dates from the final elevation of the sea-level after the last low level of the Last Glaciation, whereby the then existing landmasses were separated finally into their constituent islands. While the present subspecies and species of the 'bird-wing' butterflies are approximately of Holocene and late Pleistocene origin respectively, the phylogenetic stages previous to these two belong to the late Tertiary. The author computes that the evolution of the Troides group as a whole has occupied a period of between three and twelve million years.

Two outstanding problems concerned with the distribution of the 'bird-wing' butterflies are the overlap of the two major groups in the Moluccas, and the curious discontinuous distribution of ancestral Ornithoptera, which occurred in the Moluccas and Solomons and was absent from New Guinea. It may be mentioned that one or two of the present-day species of Euploea Fabricius (Danaidæ) show a similar hiatus in distribution so far as New. Guinea is concerned. Dr. "Zeuner considers that both these anomalies are explicable on the theory of continental drift. If New Guinea has advanced to its present position from a more southerly one during the Tertiary and Pleistocene and pushed the Moluccas and Solomons apart, and the Moluccas have been moved round from a position whereby the northern Moluccas occupied a more easterly site than at present, then these distributional problems are resolved. A. Steven Corbet. 